
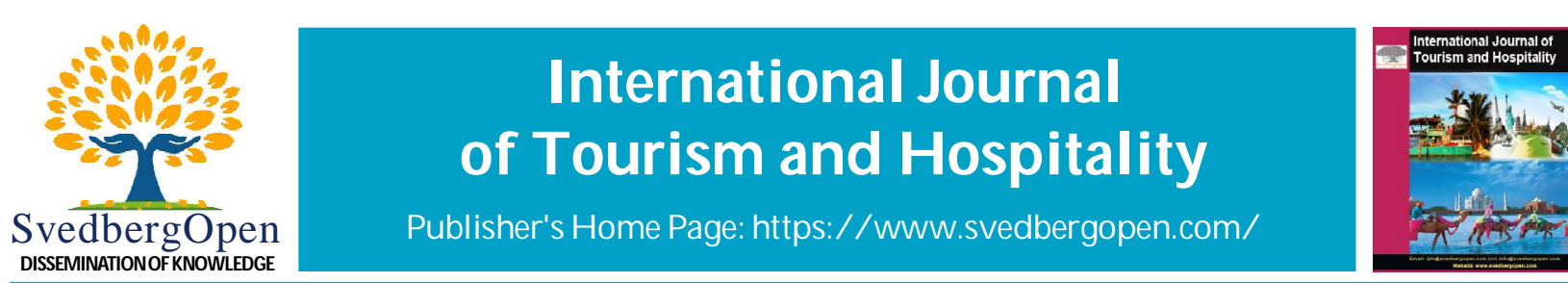

Case Study

Open A ccess

\title{
Analysis of performance in tourism businesses: A case study in Binh Dinh, Vietnam
}

\author{
Ngoc Tien Nguyen ${ }^{1}$ and Thi Le Hang Nguyen ${ }^{2 *}$ \\ ${ }^{1}$ Faculty of Economics and Accounting, Quy Nhon University, Binh Dinh Province, Vietnam. E-mail: nguyenngoctien@qnu.edu.vn \\ ${ }^{2}$ Faculty of Economics and Accounting, Quy Nhon University, Binh Dinh Province, Vietnam. E-mail: ntlhang @qnu.edu.vn
}

\section{Article Info}

Volume 1, Issue 3, July 2021

Received : 17 March 2021

Accepted : 12 June 2021

Published : 05 July 2021

doi: $10.51483 /$ IJTH.1.3.2021.21-35

\begin{abstract}
This study is designed to examine and propose the financial and non-financial norms used to analyze the operation efficiency of financial and economic aspects in tourism enterprises in Binh Dinh, Vietnam. The study surveyed 140 tourism enterprises in Binh Dinh, Vietnam, according to four groups of business sizes, including large-scale, medium-sized, small-scale, and micro-scale enterprises. The survey method was survey form, interview, and descriptive statistics, analysis of variance (ANOVA); exploratory factor analysis (EFA) analysis for analysis. Research results show that (i) The national norm system analyzing operation efficiency is not suitable for analyzing operation efficiency of enterprises; (ii) The enterprises' norm system analyzing operation efficiency is most of the enterprises just care about norms relating to sales. This means that the tourism enterprises do not evaluate operation efficiency thoroughly, and the productivity norms, profitability, non-financial indicators have not been concerned yet. At the same time, Analyzed EFA results are divided into six different groups of new factor affect to operational efficiency in tourism enterprises. Since then, this study has suggested improvement the norms system analyzing operation efficiency of the tourism enterprises in Binh Dinh, Vietnam.
\end{abstract}

Keywords: Analytical indicators, Business efficiency, Enterprises, Tourism business

(C) 2021 Ngoc Tien Nguyen and Thi Le Hang Nguyen. This is an open access article under the CC BY license (https://creativecommons.org/licenses/by/4.0/), which permits unrestricted use, distribution, and reproduction in any medium, provided you give appropriate credit to the original author(s)and the source, provide a link to the Creative Commons license, and indicate if changes were made.

\section{Introduction}

Binh Dinh is on the South Central Coast of Vietnam, a potential region for tourism development. Although tourism business efficiency plays a vital role in socioeconomic development, tourism business characteristics are affected by many different factors. Thus, it is essential to choose indicators and criteria to view social-economic efficiency. Over the years, international and domestic researches have reported financial-economic aspects, whereas the non-financial aspects, social efficiency, and norm system analyzing tourism business have not been mentioned.

This study is designed to examine and propose the financial and non-financial norms used to analyze the operation efficiency of both financial and economic aspects in tourism enterprises. To reach the primary purpose, there are some specific issues which should be addressed: (i) Analyzing the particular characteristics influencing on operation efficiency and efficiency norm system of tourism enterprises, (ii) Identifying the operation efficiency and the characteristics of norm system evaluating the efficiency of tourism enterprises, (iii) Evaluating the norm system of operational efficiency

\footnotetext{
* Corresponding author: Thi Le Hang Nguyen, Faculty of Economics and Accounting, Quy Nhon University, Binh Dinh Province, Vietnam. E-mail: ntlhang@qnu.edu.vn
} 
in tourism businesses in Binh Dinh, (iv) Proposing a norm system analyzing operation efficiency for the tourism enterprises in Binh Dinh, Vietnam.

(1) Object of study: The theoretical and fundamental issues of the norm system affecting on operation efficiency of the tourism enterprises in Binh Dinh. The principles and opinions of improving this norm system are also presented; and (2) Scope of the study: (i) In term of content, the aspects related to the norm system of operation efficiency, (ii) In term of space, 140 tourism enterprises in Binh Dinh.

Question of study: (1) Overal question: Which norm system is suitable for analyzing operation efficiency of tourism enterprises in Binh Dinh, Vietnam?; (2) Specific questions: (i) What are characteristics of the norm system analyzing operation efficiency of the tourism enterprises?, (ii) How is the current norm system analyzing operation efficiency of tourism enterprises in Binh Dinh, Vietnam?, (iii) Which solutions and petitions are suitable for improving the norm system analyzing operation efficiency of the tourism enterprises in Binh Dinh, Vietnam?

\section{Research Methodology}

(1) Research Design: Based on the literature, the author proposed evaluating indicators, designed questionnaires and scales, then using quantitative and qualitative methods to analyze with 140 observations. Descriptive statistics, test means; analysis of variance (ANOVA); exploratory factor analysis (EFA) are also used in this study. After that, the author discussed the results and conclusions to give some solutions. (2) Data gathering: (i) Date source, the secondary source is directly collected from the actual surveys and annual financial reports, and the primary source is from investigation and taking the expert advice; (ii) Gathering data, the designed questionnaire is primary medium to collect data. The official questionnaire is designed by three steps: Step 1: Designing the draft, Step 2: The draft is consulted by the professional experts, Step 3: Designing the official questionnaire. (3) Data processing and analyzing method: There are 103 valid responses collected from the survey. To process and analyze data, the author applied SPSS software with analyzing and testing tools, such as, (i) Sample statistics; (ii) Descriptive statistics and test mean; (iii) ANOVA; (iv) EFA.

Structure of research: This study includes six parts, the next part is the overview of the norm system analyzing operation efficiency of the enterprises, Part 3 is the academic establishment of the norm system analyzing operation efficiency of the tourism enterprises, Part 4 is the results of studying the norm system analyzing operation efficiency of the tourism enterprises in Binh Dinh, Part 5 is improvement the norm system analyzing operation efficiency of the tourism enterprises in Binh Dinh, Vietnam and Part 6 is the conclusion.

\section{Overview of the norm system analyzing operation efficiency of the tourism enterprises}

\subsection{International researches}

In the past years, many researchers were mentioning the aspects of economic and social efficiency: LeNin (1995) "Reaching the highest profit with the lowest cost is the aim of economic activities"; Samuelson and Dnorlhau (1997) "Efficiency is effectively using resources of the economy to satisfy the demand of people."

The current researches are concentrated on different financial and operating aspects of efficiency: (1) Singh and Schmidgall (2002) studied and mentioned the importance of the financial indices analyzing operation efficiency in the set of 36 financial indices used by the financial managers; (2) Lin and Rowe (2005) or (3) Tseng et al. (2007) evaluated operation efficiency by financial indices, such as the Return on Asset (ROA); the Return on Equity (ROE); the Return on Debt; the Return on Sales (ROS); (4) Riggo (2007) and (5) the Association of Chartered Certified Accountants (the financial indices perform ACCA, 2010a, 2010b) the operation efficiency; (6) Kaplan and Norton (1996) the operation efficiency is evaluated in four aspects: (i) finance, (ii) customer (iii) internal management process, (iv) studying and development.

In conclusion, these studies are instrumental in Vietnam. However, they did not mention the social efficiency norm system. This is their weakest point, the space for this thesis developed in both theoretical and reality.

\subsection{The domestic researches}

In the past studies, Nguyen (2004), the operation efficiency is not only the comparison between input costs and results; Do (1994), the operation efficiency is the overall socioeconomic base to choose projects or decisions of operation in any field and any time.

In textbooks, monograph books, the indices of operation efficiency is presented, such as: asset/ inventory/ incomings efficiency; asset/ inventory/receivable turnover; return on sales/short-term asset/long-term asset/equity/cost.

In other studies: (1) Nguyen (2008), Huynh (1999) the operation efficiency indices need to be evaluated on efficient and profitable aspects of manufacturing factors; (2) Nguyen (2008), Do (2012), and Tran (2012) analyzing business 
efficiency of particular enterprises is based on comparing results with costs or inputs, but characteristics of each field should be considered because they have a significant impact on evaluating the business efficiency and reflecting the level of using resources of enterprises; (3) National Administration of Tourism (2008), Nguyen (2009), Nguyen and Pham (2009) some of the indices analyzing tourism business operation efficiency are total of customers, total revenue of tourism business, the capacity of using a room, etc.; (4) Tran (2006) and Nguyen (2012) the tourism business operation efficiency indices are performed as statistical analyzing norms.

In summary, these researchers only presented the economic efficiency norms clearly, whereas the norm system analyzing social aspects is not mentioned. Besides that, for domestic studies, non-financial efficiency norms are not also given. This showed that the norm system exploring operation efficiency in both economic and social aspects had not been perfectly presented yet.

\subsection{Conclusion of overview}

There are different opinions of operation efficiency and the norm system analyzing operation efficiency in international and domestic studies.

However, because these authors only mentioned overall economic efficiency norms, it is vital to apply them in different fields appropriately. Notably, for tourism, a field affected by many specific characteristics, a career required a vital service innovation to satisfy the great demand of customers. It is essential to choose financial and non-financial norms to analyze and evaluate operation efficiency.

Besides that, social efficiency is an important measure to evaluate the contribution of these enterprises to the development of society. Nevertheless, most international and domestic studies have not mentioned and established norm systems analyzing social efficiency. This is ample space for this thesis to develop.

\section{Theoretical establishment of the norm system analyzing operation efficiency of the tourism enterprises}

\subsection{Operation efficiency and the norm system analyzing operation efficiency}

\subsubsection{Operation efficiency and signification of analyzing operation efficiency}

The essence of operational efficiency is the efficiency of resource and social labor. It is defined by comparing positive results with the costs of resources and social labor. Thus, the measure of operational efficiency is saving costs of resources and social labor. The efficiency criterion is maximizing outputs or minimizing input costs based on the resource conditions and financial resources.

Apart from that, the author concluded that: "Operation efficiency is a category reflecting using resource level of enterprises with the lowest cost and the highest benefit; benefit consists of personal and social benefits.

With this viewpoint, operation efficiency is evaluated by comparing resource and financial costs with benefit or comparing output values with resource and financial costs or each of unit of input cost. Besides that, operation efficiency should be considered in the specific space and time; and evaluated both economic and social aspects.

(1) In terms of economic efficiency: Operation efficiency is a comparative measure: comparing inputs with outputs or comparing outputs with inputs, comparing business costs with results or costs with benefits, etc.

(2) In terms of social efficiency: Operation efficiency compares labor factor and means of production with objects of production in both quantitative and qualitative correlation to create standard products/services and solute social issues.

\subsubsection{Norm system analyzing operation efficiency}

(1) In terms of overview: Operation efficiency is an economic category reflecting the correlation between using resources of the enterprises and reaching for the highest business results in the lowest cost. Operation efficiency is presented in the following equation:

Operation efficiency $=\frac{\text { Results }}{\text { Input Resources (Costs) }}$

(2) In terms of operating productivity: Operation efficiency is presented in the following equation:

$$
\text { Operating Productivity (or capacity) }=\frac{\text { Results of production }}{\text { Input Resources }}
$$


(3) In terms of operating capacity, Operation efficiency performed operating frequency of resource. The general equation:

$$
\text { Turnover of object }=\frac{\text { Net Revenue }}{\text { Value of object }}
$$

Besides that, to examine the period of each turnover, this norm is also calculated:

$$
\text { Period of turnover }=\frac{\text { Analyzing Period }}{\text { The number of turnovers }}
$$

(4) In terms of operation efficiency, the operation efficiency norm (profitability) is analyzed as this general equation:

$$
\text { Operation efficiency (Profitability) }=\frac{\text { Output profit }}{\text { Input resource or output revenue }}
$$

(5) In terms of resource cost, the low resource cost means that production capacity is high, and this is an establishment for this enterprise to improve operational efficiency. The equation is as follow:

$$
\text { Resource Cost }=\frac{\text { Input Resource }}{\text { Output Results }}
$$

In terms of internal management, to manage operations of enterprises well, the managers have to analyze their customers, internal management process, profitability from their new products, market demand, ...

In terms of social efficiency, social efficiency reflects the impacts of results on society and the environment. It can be a positive or negative impact.

In conclusion, for the author, the norm system analyzing operation efficiency is an essential and valuable instrument to evaluate the operating quality of the enterprises; it helps managers and other institutions analyzing the used resource efficiency of the enterprises. It is also a base for making suitable decisions. The norm system analyzing operation efficiency consists of economic and social norms.

\subsection{The norm system analyzing operation efficiency in the tourism enterprises}

4.2.1. The characteristics of tourism enterprises have a significant impact on the norm system analyzing operation efficiency

The tourism business is affected by many factors: (1) Value and structure of asset; (2) Structure of costs; (3) The seasonal of tourism business; (4) Local historical culture - politics; (5) Regional location - nature; (6) Social-economic condition and Customs; and (7) Political Institution.

In summary, tourism is a highly profitable business with a high interest-investment ratio. However, because of its characteristics, tourism is quite different from other businesses. Thus, we should consider determinants and choose suitable norms to analyze, evaluate operation efficiency.

\subsubsection{The norms system analyzing operation efficiency in tourism enterprises}

(1) The norm system analyzing operating capacity for business field

Total revenue from business

Total revenue $=$ Amount of resources used $\times$ Unit price served

This index shows that total revenue is created from the number of resources used in a period of production. The higher this index is, the higher resource used efficiency is and conversely.

The capacity of the current resource:

Capacity of resource $=\frac{\text { Total value of used resources }}{\text { Total value of prepared resources }} \times 100$

This index shows the percentage of used resource in a total of prepared resources. The higher this index is, the better resource is exploited, and conversely. 


$$
\text { Frequency of using resource }=\frac{\text { Total value of used resource }}{\text { Total value of prepared resource }}
$$

This index shows the level of using the resource in the total of resource prepared. The higher index is better and conversely.

The average time of using resource:

The average time of using resource $=\frac{\text { The period of time of using resource }}{\text { Total value of resource used }}$

This index shows that how long each unit of resource will be used. The higher this index is, the longer and more effective the resource is used.

The average capacity of using resource:

$$
\text { The average capacity of using resource }=\frac{\text { Total revenue earned }}{\text { Total value of resource used }}
$$

This index shows the value of revenue is earned by each unit of resource. The higher this index is, the higher value of revenue from each unit of resource is, and conversely.

The average unit price of resource used:

$$
\text { The average unit price of resource used }=\frac{\text { Total revenue }}{\text { Total value of resource used }}
$$

This index shows the average revenue of each unit resource used.

The average cost of each unit of resource used:

$$
\text { The average cost of each unit of resource }=\frac{\text { Total cost }}{\text { Total value of resource used }}
$$

This index shows the average cost of each unit of resource, the lower index is better and conversely.

(2) The norm system analyzing operational productivity and efficiency of tourism enterprises:

Operating productivity (turnovers) of resources:

$$
\text { Operating productivity (turnovers) of resource }=\frac{\text { Output results }}{\text { Input resources }}
$$

This index shows that the number of input resources spent to get a unit of output result. The higher this index is, the higher the turnover of input resource is and conversely.

The period of time of a resource turnover:

The period of time of a resource turnover $=\frac{\text { The studied period }}{\text { The number of turnover of each resource }}$

This index shows that how long the period of resource turnover is. The lower this index is, the more efficient the input resource is used and conversely.

(3) The norm system analyzing interest capacity of enterprises:

$$
\text { The interest capacity coefficient }=\frac{\text { Output profit }}{\text { Input resource, } \text { input cost, } \text { or output results }}
$$

This norm shows how many input resource units, units of input cost or units of output results are cost to get a unit of output profit. The higher this norm is, the higher the interest capacity of enterprises is and conversely. 
(4) The norm system analyzing social efficiency of enterprises:

The contribution level to the gross domestic product: This norm shows that the production value of the enterprises contributes to the national and local growth rate. The higher this norm is, the higher the contribution level is and conversely.

The contribution level to the State Budget: The higher value of contribution level means that the enterprise operates more efficiently and conversely.

The capacity of labor hired and the average income of labor: the increase of these norms means that the enterprise expands its operations and pays higher incomes for its labors and conversely.

\section{Results of studying the norm system analyzing operation efficiency of the tourism enterprises in Binh Dinh, Vietnam}

\subsection{Overview of the tourism enterprises in Binh Dinh, Vietnam}

\subsubsection{History of foundation and development}

Previous 2006: In this period, most of the tourism enterprises are small and state-owned ones established to serve tourism development based on the policy of the State and Party.

From 2006 up to now: This is the most developing period of tourism enterprises in Binh Dinh. With more transparent investment policies, the new Enterprise Law, and strategy “Tourism Plan Correction in the period up to 2020", many new enterprises have been established and developed.

\subsubsection{Characteristics of the organization structure of operating management and financial management}

Firstly, in the tourism enterprises, the operating and financial management structure is divided into four ranks: (1) Shareholders Board, (2) Managers Board, (3) Board of Directors, (4) Other directly under offices and committees.

Secondly, for tourism limited liability companies, there are three ranks in managing structure: (1) Member Council, (2) Board of Directors, (3) Other offices.

Thirdly, for private tourism enterprises, the managing structure includes (1) Director (Owner of enterprises), (2) Other directly under offices.

\subsubsection{Characteristics of operation}

In terms of business field: Hotel business makes up the highest level, at 50.49\%, eating and drinking accounting for $30.1 \%, 13.59 \%$ for entertainment and traveling standing at the lowest level, at $5.83 \%$.

In terms of operating period: most enterprises are under 5-year and 5-10 year companies, with $41.75 \%$ and $40.78 \%$; and the rest of $17.47 \%$ for enterprises established over one decade ago.

In terms of enterprise size: in Binh Dinh, most of the enterprises are small and medium enterprises, with $66.02 \%$ for the small and $22.33 \%$ for medium companies. The super small one even makes up $4.85 \%$.

In terms of le gal form: the rate of the limited liability enterprise is $66.02 \%, 35.92 \%$ for a private company, and $8.74 \%$ for a joint-stock company.

In terms of the number of labor: $86.41 \%$ is $10-50$ employee enterprise.

\subsection{Reality of the norm system analyzing operation efficiency in the tourism enterprises in Binh Dinh, Vietnam}

\subsubsection{Method of research}

To study, the importance and popularity level of the norms analyzing operation efficiency is evaluated by following scales and tools:

\section{(1) Evaluating scales:}

For importance level of the norm: 1 = "Not important"; 2 = "Slightly important", 3 = "Normal", 4 = "Important", 5 = "Very important".

For popular level of using: 1 = "Almost never", 2 = "Sometimes", 3 = "Periodic", 4 = "Often", 5 = "Usually".

The value of scale is the average value (mean) of observed variables. 


\section{(2) Descriptive Statistics:}

Descriptive statistics is used to analyze the means of the operation efficiency norms in terms of importance and popularity. This result will show that in the viewpoint of tourism enterprises, whether the norm analyzing operation efficiency is essential or not?

\section{(3) ANOVA analysis:}

ANOVA analysis compares the means of operation efficiency norms between four enterprise groups: large, medium, small and supersmall. Because of the difference of average scores, by ANOVA analysis, the authors will examine: whether there is a difference in means between these groups or not? If yes, which groups will have this difference.

\section{(4) Exploratory Factor Analysis (EFA):}

In this study, new determinants affecting operation efficiency and norms analyzing operation efficiency in the tourism enterprises are examined by EFA.

\section{(5) Content of study:}

The primary norm systems present content of analyzing operation efficiency in Binh Dinh tourism enterprises: (1) Norms analyzing operation efficiency in law; (2) Norms reflecting operation capacity; (3) Norms analyzing operating capacity and productivity of enterprises; (4) Norms analyzing the profitability of enterprises; (5) Norms analyzing social efficiency of enterprises.

In terms of reality, the author evaluates two aspects: importance level and popularity level of norm analyzing operation efficiency.

In terms of enterprises, groups analyzed operation efficiency: there are four groups: large, medium, small, and super small enterprises.

\subsubsection{The norm system analyzing operation efficiency in law regulation}

(1) Descriptive statistics analysis:

(i) In terms of the importance level of norms: the mean of total turns of the visitor is less than $3(<3.0)$, it means that for most of the enterprises, this norm is not essential; the mean of profit estimated is 3.1, this norm is typical; the mean values of other norms are approximately 4 , this shows that these norms are fundamental.

(ii)In terms of the popular level of using norms: the mean values of all of the legal forms are more than 3 (one is approximately 4 , others are more than 4), this shows that all of the enterprises usually use these norms for their financial reports in law.

(iii) In conclusion, although the total of turns of visitor and profit (estimated) are not evaluated precisely and suitably, most enterprises have to report in regulation. There is unsuitability and restriction in publishing norms analyzing operation efficiency.

(2) ANOVA analysis:

(i) In terms of the importance level of norms between enterprise groups: the Sig values of norms between the enterprise groups is $\mathrm{Sig}=0.035<0.05$. This means that there is a difference in evaluating the importance level of norms between the enterprise groups. To clear this issue, the author carried out posteriorly verification (Post) of LSD with the result: the value of correlations between big and small enterprises is $\mathrm{Sig}=0.011<0.05$, this means that the evaluation of importance level between these groups is different, the importance level of evaluating other norms is same.

(ii)In terms of the popular level of using norms between enterprise groups: With $\mathrm{Sig}=0.096>0.05$, there is the same in the popular level of using norms analyzing operation efficiency between groups.

(iii) In conclusion: Whereas the popular level of using norms analyzing operation efficiency is similar, the importance of norms is different between big and small enterprises.

\subsubsection{The norm system analyzing operation efficiency applied in enterprises}

\section{(1) Descriptive statistics analysis:}

(i) Reality of evaluating the importance level of norms:

The norm group analyzing operation capacity for field business: Mean values of all norms analyzing operation are from 3.19 to 4.86 . This shows that for most enterprises, these norms are typical and essential. 
The norm group analyzing operating capacity and efficiency, profitability (profit capacity): the average value of long-term asset turnover is 2.39 and $2.19(<3.0)$ for the economic profit capacity. This shows that these norms are not crucial in analyzing operation efficiency. Other norms are normal and essential for enterprises with average values from 3.25 to $4.74(>3.0)$.

For the norm group analyzing social efficiency: All average values of norms analyzed, from 3.58 to 4.83 (>3.0), show that most of these norms are very important.

(ii)Reality of evaluating the popular level of using the operating capacity norms for field business:

Hotel Business: Because the average values of norms are more than $3(>3.0)$, these norms are used popularly in enterprises.

Eating and drinking business: with the average values of norms more than $3(>3.0)$, these norms are used popularly in enterprises.

Travelling Business: Because the average values of norms are more than $3(>3.0)$, these norms are used popularly in enterprises.

Entertainment Business: Because the average values of norms are more than $3(>3.0)$, these norms are used popularly in enterprises.

(iii) Reality of evaluating the popular level of using the operating capacity and productivity, profit capacity norms:

The norms analyzing operating capacity and productivity of enterprises: Most of the enterprises do not concern with long-term asset turnover. For more liquid assets, the enterprises only use turnover indices to analyze, such as short-term asset turnover, inventory turnover, and incoming turnover, whereas the period of each turnover is not concerned.

The norms analyzing profit capacity of enterprises: Most of the enterprises do not care about economic profit capacity of assets, while three norms analyzing profit capacity are focused on analyzing: profit capacity of asset, profit capacity of sales, and profit capacity of equity. The enterprises do not also care about the profit capacity of short-term and long-term assets. For the big enterprises, the profit capacity of share is analyzed.

(iv) Reality of evaluating the popular level of using norms analyzing social efficiency: The enterprises just care about local budget contribution, solving labor, and advertising local culture jobs.

\section{(2) ANOVA analysis:}

(i) ANOVA Analysis of the importance level of norms between enterprise groups:

The importance level of norms analyzing operating capacity for field business between enterprise groups: With $\mathrm{Sig}<0.05$, the importance level of norms is similar in the eating and drinking business, whereas the rest is different. The results of Posteriority Verification (Post hoc) of LSD: Evaluating the importance level of norms is different between the small, medium enterprises and the super small.

The importance level of norms analyzing operating capacity and productivity, social efficiency: With Sig >0.05, there is a similarity in evaluating the importance of norms analyzing operating capacity and productivity, profitability, and social efficiency between the enterprises.

(ii) ANOVA Analysis of the popularity level of using norms between enterprise groups:

The popularity level of using norms analyzing operating capacity for field business: With $\mathrm{Sig}<0.05$, the popularity level of using norms analyzing operating capacity in the entertainment business is different between enterprises, the rest is similar. The results of Posteriority Verification (Post): for the entertainment business, there is a difference between the super small enterprises and the big, medium, small ones; for the rest, there is the similarity between the big, medium, and small.

The popularity level of using norms analyzing operating capacity and productivity and social efficiency between enterprise groups: Sig. Value of norms analyzing operating capacity and productivity and profitability is less than 0.05. It means that the popularity level of using social efficiency norm is similar between groups. The others are different. Posteriority verification (Post) shows that there is a difference between the big and the small, medium, super small enterprises, between the small and super small; the rest is similar between groups.

(iii) Analysis factors affecting operation efficiency:

The results show that: 
Sig. Values of the political institution, local policy, investment status and human resource of enterprise, the seasonal of tourism business are more than 0.05 ( $\mathrm{Sig}>0.05$ ). This means that there is no basis to reject the hypothesis. With the means approximately $4(=4.0)$, these factors have a significant impact on the operation efficiency of tourism businesses.

The factors: natural conditions, geographic region have Sig value less than 0.05; but the average values are more than 4 (the gap is more than 0.19). This shows that these factors also influence on operation efficiency of the tourism businesses.

Infrastructure for tourism, means of transport have Sig value smaller than 0.05 , but the means are more than 4 (the gaps are more than $0.796 ; 0.834)$. This shows that these factors affect on operation efficiency of tourism enterprises strongly.

Others have means smaller than $4(<4.0)$ (the gaps are negative) and Sig $<0.05$. Thus, their affecting level is average. In conclusion, the Operation efficiency of tourism enterprises is affected by many internal and external factors.

\section{(iv) Exploratory Factor Analysis (EFA):}

Analyzed results are divided into 6 different groups of new factor: Group 1: (1) Tour availability, (2) Price and fees of service, (3) Social public order; Group 2: (1) Folk Festival/Fair, (2) Diversification of restaurant and food, (3) Shopping, Souvenir; Group 3: (1) Infrastructure and means of transport, (2) Friendliness of local citizen; Group 4: Natural places, (2) Geographic position, (3) Staying place; Group 5: Quality of related services (Banking, medical services...) and (2) Night activities; Group 6: Effect of weather and climate.

In conclusion: Factors and groups of new factor exploration have an essential role in evaluating the factors and building mode of factors affecting operational efficiency. Apart from that, the author proposed some solutions to improve the norm system analyzing operation efficiency.

\subsection{Evaluating the reality of norm system analyzing operation efficiency of tourism enterprises in Binh Dinh,} Vietnam

(1) Sphere of reflection:

(i) The national norm system analyzing operation efficiency: This norm is not suitable for analyzing the operation efficiency of enterprises.

(ii)The enterprises' norm system analyzing operation efficiency:

The norms reflecting operation capacity for field business: Most enterprises just care about norms relating to sales. This means that the tourism enterprises do not evaluate operation efficiency thoroughly.

The norms analyzing operation capacity and productivity: Whereas the operation capacity is typical in enterprises. The productivity norms have not been concerned yet.

The norm analyzing the profitability of enterprises: Three norms: Return on Sales (ROS), Return on Asset (ROA), and Return on Equity (ROE) is analyzed by the enterprises. It is not enough.

The norm analyzing social efficiency of enterprises: It seems to be that most of the enterprises are not concerned with the social efficiency norms. Their contribution is performed by tax and the number of jobs solved.

(2) Quantity, name, the function of the norm:

In terms of quantity of norms: There are a few prevalent norms used in enterprises. It is also different between enterprises.

In terms of the name of norms: Despite the same essence, the name of the norm is not homogeneous between enterprises.

In terms of the function of the norm: There is a difference in the function of norms between enterprises. Notably, both values and the theoretical function of many norms in the annual report are not correct for the super small enterprises.

(3) The unification of norm: There is a big difference in norms analyzed between enterprise groups for the size and field business.

(4) The determinant group: The determinants of operation efficiency and norm system analyzing operation efficiency can be divided into four groups: (1) Institution, Policies, (2) Field characteristics, (3) Internal factors, (4) External factors. 


\section{Improvement the norms system analyzing operation efficiency of the tourism enterprises in Binh Dinh, Vietnam}

\subsection{The opinion and principle for improving the norms system analyzing operation efficiency of the tourism enterprises in Binh Dinh}

\subsubsection{Opinion for improving}

Improvement the norms system is analyzing operation efficiency of the tourism enterprises in Binh Dinh is based on opinions: (1) State regulations of accounting, statistical report and other legal rules related to tourism, (2) Being suitable for tourism characteristics, (3)Making sure that operation and resource efficiency can be evaluated entirely and exactly, (4) Making sure that the operation efficiency can be evaluated entirely from resource exploitability to using efficiency and profitability, (5) Being evaluated both social and economic efficiency, (6) Making sure that users can understand completely and apply it in reality, and (7) Suiting the international development trend of operation efficiency analysis; especially, paying attention to the non-financial norms.

\subsubsection{Principle of improvement}

Principle of suitability: (1) Suiting the development and improvement of the standard of accounting in Viet Nam in the reform and integration process, (2) Suiting the characteristics of tourism business, (3) Suiting the size of enterprises, (4) Suiting infrastructure condition, human staff of the enterprise.

Principle of flexibility: The enterprises can apply solutions flexibly to catch up with the changes of the actual situation

Principle of synchronization: Solutions can be suitably evaluated in all aspects: institution of State, policies of the organism in charge, and enterprise regulations.

Principle of feasibility: The solutions can be applied in reality.

Principle of information fitting users: Information published is diverse and sufficient for users.

\subsection{Solutions for improving the norm system analyzing operation efficiency of tourism enterprises in Binh Dinh}

The norm system improved can be classified as a flowing Table 1:

Table 1: The norm system analyzing operation efficiency of tourism enterprises in Binh Dinh

\begin{tabular}{|c|c|c|c|c|}
\hline No. & Norm & Main users & $\begin{array}{l}\text { Characteristics } \\
\text { of norm }\end{array}$ & $\begin{array}{l}\text { Evaluating } \\
\text { purpose }\end{array}$ \\
\hline $\mathbf{A}$ & \multicolumn{4}{|c|}{ The norm system analyzing operation efficiency reported in law } \\
\hline 1 & $\begin{array}{l}\text { Total of tourist turns in a period- Classified } \\
\text { by nation, region-Classified by visitor source }\end{array}$ & $\begin{array}{l}\text { Organism in charge } \\
\text { of tourism }\end{array}$ & Non-finance & Social efficiency \\
\hline 2 & $\begin{array}{l}\text { Material facilities serving tourists- } \\
\text { - The number of rooms (seats) } \\
\text { - Capacity of using rooms (seats) }\end{array}$ & Organism in charge of tourism & Non-finance & Economic efficiency \\
\hline 3 & Total net revenue by field & Organism in charge of tourism & Finance & Economic efficiency \\
\hline 4 & $\begin{array}{l}\text { The number of labors (end of the period) } \\
\text { - The number of redundancy } \\
\text { - The number of new employees }\end{array}$ & Organism in charge of tourism & Non-finance & Social efficiency \\
\hline 5 & The average income & Organism in charge of tourism & Finance & Social efficiency \\
\hline 6 & Contribution to local budget in the period & Organism in charge of tourism & Finance & Social efficiency \\
\hline 7 & Pretax profit in the period & Organism in charge of tourism & Finance & Economic efficiency \\
\hline 8 & The number of new service in the period & Organism in charge of tourism & Non-finance & Social efficiency \\
\hline 9 & The number of complainers in the period & Organism in charge of tourism & Non-finance & Social efficiency \\
\hline
\end{tabular}


Table 1 (Cont.)

\begin{tabular}{|c|c|c|c|c|}
\hline No. & Norm & Main users & $\begin{array}{c}\text { Characteristics } \\
\text { of norm }\end{array}$ & $\begin{array}{c}\text { Evaluating } \\
\text { purpose }\end{array}$ \\
\hline
\end{tabular}

B The norm system analyzing operation efficiency in tourism enterprises

I The norm group analyzing operation capacity by field business

$1 \quad$ Staying business

\begin{tabular}{|l|l|l|l|l|}
\hline 1.1 & Revenue of room (bed) & Managers, Owners, Investors & Finance & Economic efficiency \\
\hline 1.2 & Rate of revenue by kind of rooms & Managers, Owners, Investors & Finance & Economic efficiency \\
\hline 1.3 & The capacity of using room (bed) & Managers, Owners, Investors & Non-Finance & Economic efficiency \\
\hline 1.4 & Rate (turnover) of using room (bed) & Managers, Owners, Investors & Non-Finance & Economic efficiency \\
\hline 1.5 & Rate of customers and reserved seats & Managers, Owners, Investors & Non-Finance & Economic efficiency \\
\hline 1.6 & The average period of staying & Managers, Owners, Investors & Non-Finance & Economic efficiency \\
\hline 1.7 & The average price of room (bed) & Managers, Owners, Investors & Finance & Economic efficiency \\
\hline 1.8 & Labor productivity of employee & Managers, Owners, Investors & Finance & Economic efficiency \\
\hline 1.9 & The average cost per room & Managers, Owners, Investors & Finance & Economic efficiency \\
\hline 1.10 & Rate of revenue by room (bed) & Managers, Owners, Investors & Finance & Economic efficiency \\
\hline 1.11 & Rate of profit by room (bed) & Managers, Owners, Investors & Finance & Economic efficiency \\
\hline
\end{tabular}

2 Drinking and eating business

\begin{tabular}{|c|c|c|c|c|}
\hline 2.1 & $\begin{array}{l}\text { Revenue of drinking and eating business, } \\
\text { hiring conference room }\end{array}$ & Managers, Owners, Investors & Finance & Economic efficiency \\
\hline 2.2 & Rate of revenue by kind of lines of business & Managers, Owners, Investors & Finance & Economic efficiency \\
\hline 2.3 & The capacity of using restaurant (seats) & Managers, Owners, Investors & Non-finance & Economic efficiency \\
\hline 2.4 & Rate (turnover) of using restaurant (seats) & Managers, Owners, Investors & Non-finance & Economic efficiency \\
\hline 2.5 & Rate of customers and booked seats & Managers, Owners, Investors & Non-finance & Economic efficiency \\
\hline 2.6 & The average revenue of restaurant (seats) & Managers, Owners, Investors & Finance & Economic efficiency \\
\hline 2.7 & The average of serving & Managers, Owners, Investors & Finance & Economic efficiency \\
\hline 2.8 & Labor productivity of the employee & Managers, Owners, Investors & Finance & Economic efficiency \\
\hline 2.9 & The average cost per serving & Managers, Owners, Investors & Finance & Economic efficiency \\
\hline 2.10 & Rate of profit by the restaurant (seats) & Managers, Owners, Investors & Finance & Economic efficiency \\
\hline \multicolumn{5}{|c|}{3 Traveling business } \\
\hline 3.1 & Revenue of traveling business & Managers, Owners, Investors & Finance & Economic efficiency \\
\hline 3.2 & Rate of traveling business by kind of tours & Managers, Owners, Investors & Finance & Economic efficiency \\
\hline 3.3 & The capacity of transport units & Managers, Owners, Investors & Non-finance & Economic efficiency \\
\hline 3.4 & Rate (turnover) of using tour services & Managers, Owners, Investors & Non-Finance & Economic efficiency \\
\hline
\end{tabular}




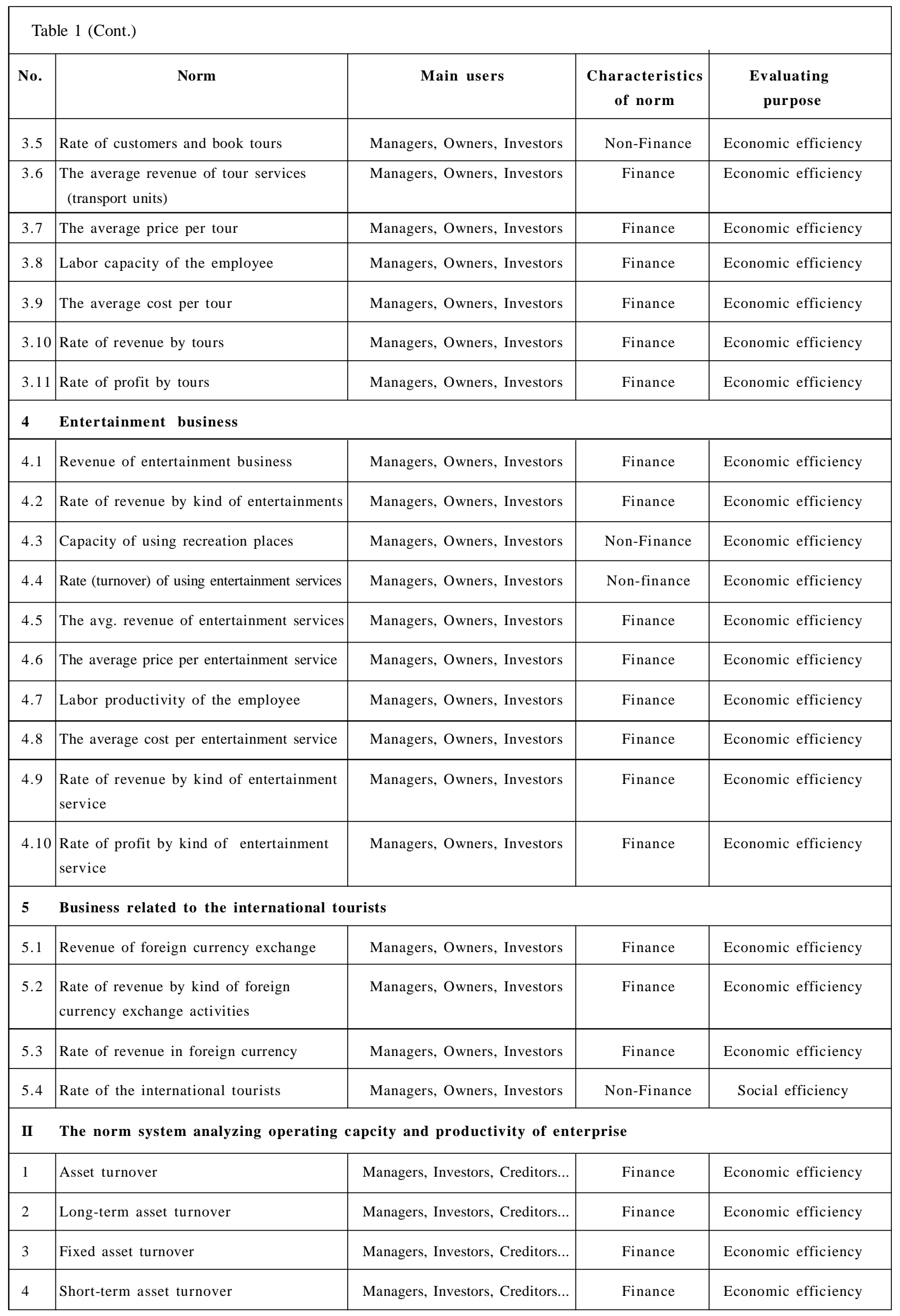




\begin{tabular}{|c|c|c|c|c|}
\hline No. & Norm & Main users & $\begin{array}{c}\text { Characteristics } \\
\text { of norm }\end{array}$ & $\begin{array}{l}\text { Evaluating } \\
\text { purpose }\end{array}$ \\
\hline 5 & Inventory turnover & Managers, Investors, Creditors... & Finance & Economic efficiency \\
\hline 6 & Receivable turnover & Managers, Investors, Creditors... & Finance & Economic efficiency \\
\hline 7 & Period of time of an asset turnover & Managers, Owners, Investors & Finance & Economic efficiency \\
\hline 8 & $\begin{array}{l}\text { Period of time of a long-term asset } \\
\text { turnover }\end{array}$ & Managers, Owners, Investors & Finance & Economic efficiency \\
\hline 9 & $\begin{array}{l}\text { Period of time of a short-term asset } \\
\text { turnover }\end{array}$ & Managers, Owners, Investors & Finance & Economic efficiency \\
\hline 10 & Period of time of an inventory turnover & Managers, Owners, Investors & Finance & Economic efficiency \\
\hline 11 & Period of time of a receivable turnover & Managers, Owners, Investors & Finance & Economic efficiency \\
\hline \multicolumn{5}{|l|}{ III } \\
\hline 1 & Return on Sales (ROS) & Managers, Owners, Investors & Finance & Economic efficiency \\
\hline 2 & Return on Asset (ROA) & Managers, Owners, Investors & Finance & Economic efficiency \\
\hline 3 & Return on Equity (ROE) & Managers, Owners, Investors & Finance & Economic efficiency \\
\hline 4 & Return on long-term asset & Managers, Owners, Investors & Finance & Economic efficiency \\
\hline 5 & Return on short-term asset & Managers, Owners, Investors & Finance & Economic efficiency \\
\hline 6 & Basis Return on asset & Managers, Owners, Investors & Finance & Economic efficiency \\
\hline 7 & Return on Investment (ROI) & Managers, Owners, Investors & Finance & Economic efficiency \\
\hline 8 & Return on operating capital & Managers, Owners, Investors & Finance & Economic efficiency \\
\hline 9 & Return on share & Managers, Owners, Investors & Finance & Economic efficiency \\
\hline \multicolumn{5}{|c|}{ IV The norm group analyzing social efficiency of enterprise } \\
\hline 1 & $\begin{array}{l}\text { New tourist service innovation and } \\
\text { introduction index }\end{array}$ & Managers, Owners, Investors & Non-Finance & Social efficiency \\
\hline 2 & Index of satisfying demand of tourists & Managers, Owners, Investors & Non-Finance & Social efficiency \\
\hline 3 & Success of new services rate & Managers, Owners, Investors & Non-Finance & Social efficiency \\
\hline 4 & Percentage of revenue by new services & Managers, Owners, Investors & Finance & Social efficiency \\
\hline 6 & Rate of waste services & Managers, Owners, Investors & Non-Finance & Social efficiency \\
\hline 7 & Satification of tourist rate & Managers, Owners, Investors & Non-Finance & Social efficiency \\
\hline 8 & Rate of new tourist development & Managers, Owners, Investors & Non-Finance & Social efficiency \\
\hline 9 & Tourist development index & Managers, Owners, Investors & Non-Finance & Social efficiency \\
\hline 10 & Serving preparation index & Managers, Owners, Investors & Non-Finance & Social efficiency \\
\hline 11 & Contribution index of enterprise & Managers, Owners, Investors & Non-Finance & Social efficiency \\
\hline
\end{tabular}




\subsection{The conditions for applying solutions for improving the norm system analyzing operation efficiency of enterprises in Binh Dinh}

(1) State and Organisms in charge: General Directorate of Tourism and Binh Dinh Service of Culture - Sports and Tourism should care about (i) Perfecting legal documents of tourism management, (ii) establishing an apparent sanction, the rewarding and publishing mechanism to force enterprises to publish accurate figures in their annual reports, (iii) promulgating preferential policies to attract investment in tourism, advertising local culture to impulse tourism business.

(2) Tourism Association: Tourism Association should set up the norm system analyzing the operation efficiency of tourism enterprises by professions and fields.

(3) Binh Dinh People' Committee: Binh Dinh People's Committee needs to concern with (i) completing the proposed norms flexibly to evaluate the operation of the enterprises more precisely, (ii) promulgating preferential policies to attract investment in tourism, (iii) Investing in a system of local schools training tourism, (iv) choosing the most notable festivals to invest and develop to national and international festivals, $(v)$ discovering and developing new tourist destinations and attached services.

(4) Tourism enterprises: Tourism enterprises should (i) strengthen awareness of the importance of operation efficiency analysis for leadership at all levels, offices, divisions, (ii) monthly, quarterly and annual analyze operation efficiency, establish a division in charge of analyzing operation efficiency, (iii) invest in material facilities and technologies for this analysis, (iv) concentrate on investing and upgrading infrastructures, innovating and diversifying tourist services.

\section{Conclusion}

In this study, the authors concentrated on solving the following issues (i) The overview of analyzing operation efficiency of the tourism enterprises in the international and domestic researches; (ii) Systematizing the overall theoretical basis of operational efficiency and the norm system of operation efficiency analysis by different viewpoints of the international and domestic researchers; (iii) Designing questionnaire, collecting data, applying quantitative and qualitative methods to analyze and evaluate reality, bringing out the restrictions of enterprises. Besides that, the authors also provided the determinant groups affecting operation efficiency in the tourism business; (iv) Apart from that, the authors proposed the opinions, principles, and solutions to improve the norm system analyzing operation efficiency of tourism enterprises in Binh Dinh, Vietnam. These norms are evaluated in financial and non-financial aspects for not only government agencies but also tourism enterprises. To use more conveniently, they are also divided into different groups. However, because data are only collected from tourism businesses in Binh Dinh, Vietnam, there should be suitable choices and adjustments to apply these norms in other places.

Moreover, although the authors mentioned the norm system in the non-financial aspect, the non-finance evaluation is different from the opinions of the analyzer. Thus, for the authors, in the following research, the enlargement of the surveyed subject, sphere, and sample size should be necessary. In these studies, the norms of non-financial efficiency should also be discovered and established.

\section{References}

ACCA. (2010a). P3. Business analysis. BBP Learning Media.

ACCA. (2010b). F5. Performance management. BBP Learning Media.

Do, H.T. (1994). Basics of corporate governance. Statistical Publishing House.

Do, H.T. (2012). Completing analysis of business efficiency in export wood processing enterprises in the South Central region. PhD Thesis. National Economics University.

Huynh, D.L. (1999). Completing the business performance evaluation criteria of state-owned enterprises. PhD Thesis. Vietnam National Library.

Kaplan, R.S. and Norton, D.P. (1996). Using the balanced scorecard as a strategic management system. Harvard Business Review.

LeNin, V.I. (1995). National Electrification Plan. Moscow Publishing House.

Lin, S. and Rowe, W. (2005). Determinants of the profitabiliy of China's regional SOEs. China Economic Review, 17 (2006), 120-141. 
Ministry of Culture, Sports and Tourism (2008). Circular No: 88/2008/TT-BVHTTDL guiding Decree 92/2007/ND-CP implementing a number of articles of the Law on Tourism on tourist accommodation. Hanoi.

Nguyen, V.T. (2004). Improving business efficiency of enterprises in the market economy. Trade Journal. 13, $24-33$.

Nguyen N.Q. (2008). Completing analysis of business performance in Vietnamese enterprises. Ministerial-level scientific research project. Hanoi.

Nguyen, T.M.H. (2008). Analysis of business efficiency in mining enterprises. PhD Thesis. National Economics University.

Nguyen, V.D. (2009). Hotel and restaurant management accountant. Ho Chi Minh City National University Publishing House.

Nguyen, V.M. and Pham, H.C. (2009). Textbook of Tourism Business Administration. National Economics University Publishing House.

Nguyen, L.A. (2012). Statistical methods of tourism business performance in Vietnam. PhD Thesis. National Economics University.

Riggo, H.E. (2007). Understanding the Financial Score. Morgan \& Claypool Publishing House.

Samuelson, P.A. and Dnorlhau, W. (1997). Economics, 15th edition. National Political Publishing House.

Singh, A.J. and Schmidgall, R.S. (2002). Analysis of financial ratios commonly used by US lodging financial executives. Journal of Leisure Property, 2, 201-213.

Tran, T.T.P. (2012). Completing analysis of business performance in joint stock companies listed on Vietnam's stock market. PhD Thesis. National Economics University.

Tran, T.K.T. (2006). Statistical study of tourism business performance. National Economics University Publishing House.

Tseng, F.M., Chiu, I.J. and Chen, J.S. (2007). Measuring business performance in the high-tech manufacturung industry: A case study of Taiwan's large-sized TFT-LCD panel companies. Omega Journal, 37(3), 686-697.

Cite this article as: Ngoc Tien Nguyen and Thi Le Hang Nguyen (2021). Analysis of performance in tourism businesses: A case study in Binh Dinh, Vietnam. International Journal of Tourism and Hospitality. 1(3), 21-35. doi: 10.51483/IJTH.1.3.2021.21-35. 